\title{
THE SYMPTOMS OR PHENOMENA FORMERLY KNOWN AS CROUP; THE DISEASES WHICH PRODUCE THEM; AND THE CLINICAL SIG- NIFICANCE OF THE VARIOUS ALLIED AFFECTIONS EMBRACED BY THE TERM.
}

\author{
BY LANGFORD SYMES, F.R.C.P. (IREL.), \&c.; \\ Physician to the Orthopædic Hospital of Ireland; \\ Physician to the Convalescent Home, Stillorgan, \&c., \&c. \\ [Read in the Section of Medicine, April 6, 1900.]
}

As a short sequel to the discussion on Mr. Croly's paper of January 26, 1900, I have thought it well to try to sum up if possible the points in which we are in accord.

When sent for to a case of "Croup" we have no idea what lies before us. We picture a child choking from a disease perhaps beyond our control, or possibly it may be but a passing spasm. Between these two extremes an infinite variety exists. They are all called "croup," but the word practically only conveys that respiration is impeded in the larynx. "We should be far better without the word. There is no such disease as croup; the word merely expresses a single symptom," " just as the terms dropsy, coma, or convulsions. It is well, howerer, for us to clearly know what it means, what is the clinical condition, and to mark some limitation for the term.

The following group of symptoms seem to me to be embraced by the term. I give you them, as I gathered them, fresh from the original at the bedside.

admund Owen, Surgeon to the Hospital for Sick Children, Great Ormond. street. 
CROUPY SYMPTOMS.

1st. Laryngeal Stridor.-A dry, croupy, tracheal wheeze heard at the bedside; while sleeping a stridulous wheeze persists. This merely indicates difficulty of breathing from some impediment or narrowing, preventing the air passing freely. The lungs are clear; the throat is clear to view, or perhaps slightly, if anything, reddened, certainly not swollen.

2nd. Cough with a barking "croupy" sound.-The fit consisting of inspiratory dyspnoea with a couple of croupy barks suddenly following. Sometimes in the middle of a fit of coughing the child gives a loud whoop as in whooping-cough, chiefly heard in convalescence.

3rd. Night Attacks.-Worse at night. About eleven o'clock the child begins to get bad attacks, often two or three during the night. It starts up in terror, gasping, wheezing, crouping, and barking very terrifying to witness; hardly any air entering, and in peril of choking. Apparently due to spasms.

4th. Great Restlessness and tossing about; also from impediment to respiration. This is in my experience a grave sign, and in fatal cases, where the child does choke, most agonising to witness. It is also the first sign by which to estimate improvement.

5th. Recession of the Chest.

Through all these the voice may be quite clear, even when stridor is alarming. These are the five symptoms for which we are summoned, and they are popularly called "croup." But to what are they due? They are merely manifestations of actual disease which underlies them. The stridor is caused by narrowing, the cough by irritation or foreign material. the night attacks by spasm, the restlessness by asphyxia, and the recession of the chest by atmospheric pressure from obstruction to the entrance of air. Clearly, then, the acute 
diseases which produce these morbid changes and croupy symptoms are all embraced by the term.

Their diagnosis is always difficult, sometimes impossible. Roughly spenking, and from a clinical standpoint, tiney seem to possess two main characteristics : in one group specific or inflammatory disease exists in the larynx (e.g., diphtheria and laryngitis), while in the other the obstruction is mainly due to spasm. They are as difficult to separate on paper as they are at the bedside, for the spasmodic cases are sometimes fatal, while the laryngitis group are seldom devoid of spasm. We may have every variety, from raging diphtheria on the one hand, to a trivial laryngismus on the other; and as this latter disease is of ten confounded with the rest it must be mentioned, though really an entirely different condition.

I propose to briefly treat of three main species :-

I. Diphtheria,

II. Laryngitis, and

III. Laryngismus.

I.-Diphtheria (Diphtheritic Laryngitis-Laryngeal Diphtheria-Menbranous Laryngitis-Diphtheritic CroupMembranuus Croup-True Croup-Secondary Croup of Dr. Stokes-Cynanche Membranacea-Cynanche Maligna).

There can be no doubt but that true croup, diphtherit, and membranous laryngitis are forms of the same disease, produced by the reception and cultiration in the body of poisonous germs. Croup is the disease when diagnosticated by the ear, diphtheria when diagnosticated by the eye, and deaths. registered as croup are, I believe, mainly due to diphtheria ; but croupy symptoms are not necessarily always due to this disease. In 1879 the Scientific Committee of the Royal Medico-Chirurgical Society affirmed the diphtherial identity of membranous croup. Some ${ }^{a}$ dissent from this, and state

a.g., Mr. Lennox Browne, F.R.C.S. 
that 14 or 15 per cent. of membranous croup are nondiphtherial, on the ground that some cases reveal diplococci and others similarly affected in the same house are also coccal. Therefore, he argues, some membranous croups cannot be strictly diphtherial or notifiable. Doubtless it is held that membranous exudation in the windpipe may be produced by mechanical and chemical irritants, and there is some evidence that membranous laryngitis has followed exposure to cold. But $I$ hold that there is also evidence that there are several varieties of the disease we now call diphtheria; some of a fœtid purulent nature, and the absence of Klebs-Löffler bacillus must not be regarded as proof that an angina is not diphtheritic: Experiments in the laboratory may give results which clinical observation entirely fails to endorse. In the present state of our knowledge it is not wise to take up a dogmatic position except to view every case of laryngitis with the greatest suspicion, as it may turn out to be diphtheria. But I agree with Mr. Edmund Owen that the more I see of sore throats with laryngeal obstruction the more firmly do I believe that they are all diphtheritic. Again, I feel in accord with the conclusion of Sydney Martin, Sims Woodhead, and Sir Richard Thorne Thorne (1892) that " there is no eviclence at present that there is any disease other than diphtheria which can produce a false membrane in the larynx." Recollect that diphtheria may be entirely confined to the larynx, to the trachea, or even the bronchial tubes without being visible.

When confronted with a case presenting the urgent croupy symptoms I have described, the points which may stamp it as diphtheria are the following :-

1. Gradual Onset.-The croup is preceded by fever. The child is sueezing or sickish for perhaps three whole days with an unaccountable feverish attack. It commences quietly and grows steadily worse. There is a slowly rising 
acute febrile period before the larynx is affected, developing croupy stridor about the fourth day. It is a microbic or miasmatic poison saturating the system and showing itself in the larynx, rising gradually to a perilous and alarming crisis about the fourth or fifth night when the child is in danger of choking.

2. The Cervical glands may be enlarged, hard, and painful.

3. Enlarged area of cardiac dulness.-I have found the heart somewhat dilated, being dull to the third rib, one finger's breadth outside the left nipple and mid-sternum. This dilatation of the heart is not constant in the commencement, and may then be found at one hour and not at another hour during the same day. I have found it well established by the ninth day.

4. It may be traced to vegetable decomposition, to foul drains, sewers, or manure heaps, which cause an initial sore throat, or perhaps direct infection. I have traced some cases to vegetable decomposition.

5. Albumen in the urine and severe illness of the child point very decidedly to diphtheria.

6. The possible discovery of membrane in the pharynx and bacteriological confirmation at once settle the question.

7. The protracted illness and slow recovery indicate diphtheria, as also a fatal ending.

8. Communication to or from others can only be diphtherial. There is sometimes a septicamic rash in diphtheria on the chest and abdomen, and the knee-jerks are occasionally absent, while the continuance of a low temperature with grave illness and croupy symptoms point to its diphtheritic nature.

II.-Laryngitis. - Two forms of laryngitis especially concern us:-(1) Acute laryngitis, and (2) Laryngitis stridulosa.

1. Acute Laryngitis (Catarrhal Laryngitis-Acute Non-membranous Laryngitis-Simple Laryngitis).

The swelling and œedema which block the way in acute 
laryngitis may sometimes produce croupy symptoms, and may present every variety from hoarseness and stridulous breathing to fatal odema of the glottis.

The distinguishing features here are :-Hoarseness of voice, the respiration has a more hissing sound, no enlarged glands, more rapid onset, no albuminuria, no special night attacks. It chiefly follows colds or chills, or succeeds to measles or whooping-cough. No alteration of the knee-jerks. No dilatation of the heart. No infection. It is hard to make a certain diagnosis, for these peculiarities may happen with diphtheria, and hence it is wise to suspect diphtheria in every case of croup.

2. Laryngitis Stridulosa (Catarrhal Sparm-False CroupPseudo-Croup-Spasmodic Croup-Spasmodic Laryngitis-Primary Croup of Dr. Stokes).

This is the disease which most closely simulates diphtheria. It is a spasmodic narrowing of the windpipe-a catarrhal spasm, having much spasm with a little catarrh. It occurs in children over three years of age, and when we are told that "my child is very subject to croup," this is the disease in question. It produces all the above "croupy symptoms," and may be of great urgency. Dr. Stokes describes fatal cases, where at the post-mortem examination the larynx was not obstructed, showing death was due to spasm. It is distinguished from diphtheria by the following special features:-

1. Very Sudden Onset. - The child goes to bed quite well, and suddenly wakes up in the night with alarming laryngeal obstruction, great distress and dyspnœa; death seems imminent, and advice is hastily summoned. The suddenness of the stridulous breathing is remarkable.

2. Occurs at Niglt.-It is very bad for some hours, and then subsides.

3. Recurrent.-We are of ten told "my child is very subject to croup," or the mother or nurse will state that the child has very often had it before. 
4. A Family Affection.-Some of the other children of the family often suffer from it.

5. Quick Recovery is the rule, and it is rarely fatal.

6. It of ten occurs in children with enlarged tonsils, or adenoids.

In one of my cases five children of the same family had it frequently for some years, and they were all affected with aclenoids.

7. It occurs in children over three years of age ( $f f$. laryngismus), and ceases when the child is 14 or 15 years old.

8. Vomiting often gives relief.

With chrouic laryngitis (syphilitic or tubercular), foreign bodies, warty growths, or stricture of the trachea, we have nothing to do at present.

III.-Lastly, Laryngismus (Child Crowing-Spasm of the Laryno-Laryngeal Asthma-Spasm of the GlottisLaryngismus Stridulus).

This is an entirely different condition, and should not be included in the term, for it does not produce croupy symptoms. A convulsive disorder of young infants, unattenderl by cough. A pure neurosis, or spasm, occurring almost exclusively in rickety infants about 18 montls old, with large fontanelles and delayed dentition, and of ten accompanied by tetany contractions of the thumbs and toes. A spasmodic affection of the larynx, causing sudden arrest of breathing, or "holding of the breath" for a few seconds in the position of expiration, followed by a "crowing" inspiration when the glottis opens and air rushes in with a stridor. It is very rare before six months or after three years. There is no fever. It occurs suddenly while the child is running about, or in the night, with no warning. There is no hoarseness, and the child is perfectly well in the intervals. The fit is started by some emotion, annoyance, fright, crying, or perhaps the irritation of adenoids or teething. It varies from a slight crowing sound to extremely dangerous fits of 
dyspncea and cyanosis, with the hands clenched, the limbs stiff, the veins turgid, and the face blue, or eren convulsions. It is mostly recovered from, but there is danger of the spasm being fatal. The epiglottis is shut down over the laryns. The attacks are frequent, sometimes $4,6,8,10$, or even 20 in a day. Many cases have the "crow," but the worst cases are the silent ones, from the complete strangulation.

Three varieties of the spasm are known:-

1. Rachitic, occurring as described above in rickets, similarly to facial irritability, tetany, or fits. This is also called "direct" spasm, signifying its direct connection with the brain, the irritation coming directly from it. A pure spasm of the muscles. No fever, coryza, or laryngeal catarrh. No cough. It is occasionally fatal, and is sometimes a cause of death under chloroform during operations for adenoids.

2. Congenital (Infantile Respiratory Spasm, Congenital Laryngeal Stridor).-Begins at or shortly after birth, when the child is a few weeks old, with laryngeal or stridulous breathing. A functional neurosis, pathology not yet determined, and recovered from by natural development in the course of the second year, disappearing before 18 months. A valvular formation of the larynx has been observed.

3. Reflex spasm-i.e., dyspnœa from enlarged bronchial or mediastinal glands. Sudden death has occurred from spasm of the glottis in cases of tuberculosis, with enlarged and caseous bronchial or mediastinal glands. ${ }^{\mathbf{a}}$

- Dr Ashby cites two cases:-

(a) A child aged one year and eight months died from croupy symptoms, in spite of tracheotomy. The post-mortenn examination showed an enlarged thymus gland flled with a tubercular abscess, and a cheesy adherent lymphatic gland was found pressing on the trachea down to its bifurcation.

(b) A boy aged three years, who was affected with croupy symptoms and choking during meals, died. The post-mortem revealed enlarged mediastinal glands, and an abscess pressing on the osophagus and trachea, fron Potts' disease of the seventh cervical and third upper dorsal vertebræ. 
The diseases, therefore, which confront us in the cases of croupy symptoms are chiefly two:-Laryngitis Stridulosa and Diphtheria, the remaining forms being more easily differentiated.

Their management is as varied as their severity. The laryngismus of infunts is cured by fresh air at the seaside, cold salt douches, meat juice, and remedies which control the nerrous instability of the underlying rickets or tuberculosis. No attempt at hot rooms or steam should be permitted.

In Laryngitis the points to be relieved are swelling of the mucous membrane and spasm. The first may be eased by a purgative dose of calomel, leeches to the throat, bleeding, ipecacuanha, and especially antimony. In a doubtful case, where the clisease was violent last year, I saw great benefit follow the exhibition of gr. $\frac{1}{48}$ th of apomorphia with each dose of antimony.

Spasm can be relieved by hot sponges, steam, and it is possible that phenacetin or antipyrin carefully given may be useful.

In suspected cases of Diphtheria (and there is always suspicion) antitoxin should be given at the earliest sign of laryngeal mischief (2,000 units for a child two years old, or 1,500 every morning for four days). This is our sheet anchor. It has also allowed cases to tide over the crisis with intubation, which formerly died.

Should these or other measures fail, and the child be in danger of. choking, the question of surgical interference arises.

There still remain intubation and tracheotomy. The surgeon is required only when sufficient air cannot enter, and the child is choking from asphyxia; but the physician has the responsibility of summoning him. What, then, are the signs of approaching asphyxia? Two especially of the foregoing croupy symptoms. - They are-(1.) Recession of the chest, and 
(2.) Restlessness; and these to my mind form the most correct indications for the further admission of air. These signs should be watched, for in fatal cases the recession increases, the head is thrown back to straighten out the trachea, the restlessness gradually gives place to unconsciousness, and the child dies asphyxiated in convulsions.

Intubation is a delicate and intricate proceeding. I have seen it tide over the crisis successfully where antitoxin had previously been given. Tracheotomy, on the other hand, is the more usual, but its results have not been hitherto encouraging.

Dr. Stokes says:- "On the performance of tracheotomy in this disease I have little to say more than express my decided dissent from it." (Diseases of the Chest, p. 219. 1837.) And almost prophetic is the advice of Mr. William Henry Porter :- "Medical men should rather turn their attention to the improvement of that internal treatment which will generally be efficacious if resorted to in time, than to look for advantage in the performance of an operation from which experience holds out such slender hopes." (Surgical Pathology of the Larynx and Trachea. Dublin, 1826.)

These quotations are 63 and 74 years old, but until the recent fulfilment of Mr. Porter's prophecy by the introduction of antitoxin, nothing has occurred to warrant the rejection of their conclusions. Now, however, we are entering on a new era in the pathology, prognosis, and treatment of these diseases, and under antitoxin tracheotomy may become more successful.

The following conclusions may, I think, be drawn:-

1. That there is no such true disease as croup, croupy symptoms being produced by a variety of different diseases.

2. That severe croupy symptoms are most likely to be due to either diphtheria or laryngitis stridulosa. 
3. That in difficult and doubtful cases we should suspect diphtheria, and treat it as such from the start with antitoxin.

4. That recession and restlessness are the two most dingerous symptoms.

5. That as antitoxin reduces the mortality of diphtheria, and enables cases to be tided over the crisis by intubation, it may possibly contribute to the future success of tracheotomy.

6. That the deaths registered as croup are mainly due to rliphtheria.

Dr. Travers Smith spoke.

Dr. Drory asked what class $\mathrm{Dr}$. Symes would put those cases under in which they had laryngitis closely resembling what they used to call croup, and which they met with in measles. He saw an enormous number of such laryngitis cases in the last epidemic, and such a number of tracheotomies had to be performed that almost all the tracheotomy tubes to be obtained in Dublin had been used up. At one time there were some 25 to 30 cases all with tubes in, but they were not diphtheritic cases, nor were they laryngismus stridulus, and most of them recorered.

Dr. Dorte recommended the use of sulphate of copper in croup.

Srr Grorge Dufrer said he quite agreed with Dr. Doyle as to the benefit of sulphate of copper in such cases as contrasted with depressant emetics. He believed they were often inclined not to give enough antitoxin, and he had never seen any bad effects follow its administration.

Mr. Croly spoke.

Dr. Parsons said that frnm his point of view diphtheria was an inflammation produced by the Klebs-Löffler bacillus, and it did not make any difference whether the inflammation was catarrhal, croupous or diphtheritic. Some other name would then have to be found for those cases of inflammation of the throat produced by other micro-organisms. Similarly, in a recent paper, Dr. J. W. Moore pointed out that the clinical term pneumonia corered a great variety of diseases, as well as the inflammation produced by the diplococcus pneumonix. In addition to $\mathrm{Dr}$. Symes' two indications for surgical interference he thought theg might also add ryanosis. 
Dr. J. W. Mnone said they would all agree with Dr. Travers Smith that the dyspnoer of diphtheria was not a night symptom, whereas that of laryngismus stridulus was essentially a night symptom. He agreed with Sir George Duffey in believing that diphtheria is often apyrexial, and if they had high fever it was probably not diphtheria. The absence of knee-jerks, however, as well as albuminuria, only appeared after toxic poisoning had taken place, and, therefore, were not reliable indications early in the disease.

Dr. LANGFord Srmes, replying, said he believed there were many varieties of the disease commonly called diphtheria. Why the night attacks which he had mentioned came on he could not tell, and it could not be said that they were indicative that the case was not diphtheritic, because he thought it was possible that a diphtheria case could have a violent spasm of the larynx as well as another. 